Article

\title{
Heterogeneous Hybrid Nanocomposite Based on Chitosan/Magnesia Hybrid Films: Ecofriendly and Recyclable Solid Catalysts for Organic Reactions
}

\author{
Metwally Madkour ${ }^{1}\left(\mathbb{D}\right.$, Khaled D. Khalil $^{2,3}{ }^{\circledR}$ and Fakhreia A. Al-Sagheer ${ }^{1, *}$ \\ 1 Chemistry Department, Faculty of Science, University of Kuwait, P.O. Box 5969, Safat 13060, Kuwait; \\ Metwally.madkour@ku.edu.kw \\ 2 Chemistry Department, Faculty of Science, Cairo University, P.O. 12613, Gisa 12573, Egypt; \\ kkhalil@taibahu.edu.sa \\ 3 Department of Chemistry, Faculty of Science, Taibah University, Yanbu 46423, Saudi Arabia \\ * Correspondence: f.alsagheer@ku.edu.kw
}

Citation: Madkour, M.; Khalil, K.D.; Al-Sagheer, F.A. Heterogeneous Hybrid Nanocomposite Based on Chitosan/Magnesia Hybrid Films: Ecofriendly and Recyclable Solid Catalysts for Organic Reactions. Polymers 2021, 13, 3583. https:// doi.org/10.3390/polym13203583

Academic Editor: Agnieszka Tercjak

Received: 17 September 2021

Accepted: 13 October 2021

Published: 17 October 202

Publisher's Note: MDPI stays neutral with regard to jurisdictional claims in published maps and institutional affiliations.

\begin{abstract}
Chitosan/magnesia hybrid films (CS-Mg) have been prepared via sol-gel process and employed as heterogeneous catalysts. An in situ generation of a magnesia network in the chitosan matrix was performed through hydrolysis/condensation reactions of magnesium ethoxide. The synthesized hybrid films were characterized using various analytical techniques, such as X-ray photo-electron spectroscopy (XPS), field emission scanning electron microscopy (FESEM) and atomic force microscopy (AFM). The hybrid films display excellent catalytic activities in Michael and Knoevenagel reactions via one pot or solvent-free approaches under microwave irradiation conditions. Chitosan/magnesia hybrid films, catalysed pyrimidine, benzochromene, coumarin and arylidenemalononitriles derivatives formation reactions occurred with highly efficient yields of $97 \%, 92 \%, 86 \%$ and $95 \%$ respectively. Due to the fact that the films are durable and insoluble in common organic solvents, they were easily separated and can be recycled up to five times without a considerable loss of their catalytic activity.
\end{abstract}

Keywords: chitosan; magnesia; heterogeneous catalyst; nanocomposites; Michael additions; Knoevenagel reactions

\section{Introduction}

Over the past several decades, increasing attention has been directed toward the development of cleaner/greener synthetic methods, including processes that produce maximum yields of products, have minimum costs, avoid the use of toxic reagents and solvents, and proceed by synthetic routes that avoid the need for isolation of intermediates [1-4]. In this context, heterogeneous catalysts have advantages over their homogeneous counterparts because they can be easily isolated from reaction mixtures using simple filtration and can then be reused. As a result, reactions promoted by heterogeneous catalysts are economical and eco-friendly [5-7]. Magnesium oxide, a heterogeneous basic catalyst, has been recently used to promote several base-catalyzed organic transformations and is also an additive in refractory, paint and superconductor products [8-11]. As one of the most abundant natural biopolymers, chitosan (CS) possesses excellent properties, such as biocompatibility, biodegradability, non-toxicity, and insolubility in most solvents. Consequently, it has been used on its own or as part of films or fibers in several applications [12-14]. Chitosan has garnered significant interest, owing to the essential role it plays in transition metal catalyzed reactions [15]. For example, chitosan-supported metal complexes are used as catalysts for Suzuki cross-coupling (CS-supported Pb) [16], Henry (Cs-supported Ti catalyst) [17] and hydroformylation (CS-supported Rh catalyst) reactions [18]. Additionally, the biopolymeric nanocomposite (CS-Pr-Me- $\mathrm{Cu}(\mathrm{II})-\mathrm{Fe}_{3} \mathrm{O}_{4}$ ) was investigated as a heterogenous 
catalyst for the oxidation of benzyl alcohols/Knoevenagel condensation [19]. Recently, we uncovered an efficient protocol for catalyzing Michael addition reactions that rely on the use of modified and non-modified chitosan as heterogeneous recyclable catalysts $[4,5]$. However, the major drawback of employing chitosan as a homogeneous catalyst is related to its propensity to form gels, which makes its separation and recovery difficult. The widespread use of heterocyclic compounds in agricultural, pharmaceutical, analytical, and medicinal chemistry areas has encouraged efforts aimed at the development of new methods to synthesize members of this wide family [20]. Molecules containing pyrimidine, coumarin, and benzopyran are highly important classes of $\mathrm{N}$ - and O-heterocycles that are widely used as valuable precursors for pharmaceutical agents [21,22]. Over the preceding decades, a considerable increase in devising microwave assisted organic processes has been apparent, due to their economic and green advantages [23].

In continuing efforts focused on the design of novel methods to prepare nanocomposites, which can be employed as heterogeneous catalyst, we have turned our attention to one pot or solvent-free approaches. Herein, we developed a method for the synthesis of pyrimidine, coumarin and chromene derivatives that rely on the use of CS-MgO nanocomposite films as heterogeneous catalysts for reactions carried out under microwave irradiation conditions. The CS-MgO hybrid nanocomposite films were prepared by incorporating magnesium ethoxide in the chitosan polymer matrix through use of the sol-gel process $[24,25]$. The morphology and size of the magnesia particles in the polymer matrix were determined using scanning electron microscopy. Studies of the utilization of the hybrid films as heterogeneous catalysts revealed that they serve as an eco-friendly recyclable catalyst and promote highly efficient Michael and Knoevenagel reactions.

\section{Materials and Methods}

\subsection{Materials}

Medium molecular weight grade chitosan (deacetylated 90\%, M = ca. 35.000), magnesium ethoxide (purity 98\%) and nano-magnesium oxide powder ( $<50 \mathrm{~nm}$ particle size) were purchased from Aldrich (Sigma-Aldrich, St. Louis, MO, USA ). All other chemicals were of analytical grade and used without further purification. All products were characterized using FTIR (Varian 610-IR microscope system, Santa Clara, CA, USA), and ${ }^{1} \mathrm{H}-$ and ${ }^{13} \mathrm{C}-\mathrm{NMR}$.

\subsection{Preparation of the Nanocomposite Films}

A solution of chitosan polymer ( $2 \mathrm{wt} . \%$ ) was prepared by dissolving it in a $2 \%$ acetic acid aqueous solution. The prepared solution was permitted to stir for $48 \mathrm{~h}$ at room temperature to obtain homogeneous solution. A certain amount of this solution and a stochiometric amount of magnesium ethoxide were added to a $50 \mathrm{~mL}$ bottle (Scheme 1). The mixture was permitted to stir for $1 \mathrm{~h}$ at room temperature. A mixture of water and ethanol with volume ratio (1:1.5) was added to the solution and then the mixture was stirred for $18 \mathrm{~h}$ at room temperature to complete the sol-gel process. This solution was then casted in Teflon petri dishes and dried at $50^{\circ} \mathrm{C}$ for $17 \mathrm{~h}$. The films were then further dried under vacuum conditions for $48 \mathrm{~h}$ at $50^{\circ} \mathrm{C}$.

\subsection{Characterization of the Chitosan-Mgo Hybrid Films}

Field emission scanning electron microscopy (FESEM) (PhotoMetrics, Inc., Huntington Beach, CA, USA) was conducted to obtain insights into the shape and size of the prepared films using a (JEOL JSM-7001F). X-ray photoelectron spectroscopy (XPS) (Axis Ultra DLD Spectrometer, Kratos, Manchester, UK) was conducted to investigate the surface elemental composition of the hybrid films using a Thermo ESCALAB 250 Xi (Thermo Fisher Scientific, Waltham, MA, USA), using monochromatic $\mathrm{Al} \mathrm{K} \alpha$ radiation $(1486.6 \mathrm{eV})$ and a pass energy of $20 \mathrm{eV}$. The XPS deconvoluted spectra were conducted using Thermo Avantage software version v5.956 (Thermo Fisher Scientific) with Gauss-Lorentz maximum iterations of 100, a convergence of 0.0001 and a Powell fitting algorithm. All the binding energy values $(\mathrm{BE} / \mathrm{eV})$ 
were corrected with regard to the adventitious Carbon $(\mathrm{C}-\mathrm{H} / \mathrm{C}-\mathrm{C})$ for $\mathrm{C} 1 \mathrm{~s}$ at $284.6 \mathrm{eV}$. The surface topography was studied using a Nanoscope-IV multimode atomic force microscope (AFM) (Nanoscience Instruments, Inc., Phoenix, AZ, USA). A scan area of $5 \mu \mathrm{m}$ was measured. The background was removed from the images using Nanoscope software. A thermogravimetry (TGA) (Mettler Toledo, Columbus, $\mathrm{OH}$, USA) was performed with a $10 \mathrm{mg}$ sample from ambient for up to $800^{\circ} \mathrm{C}$ at a heating rate of $10^{\circ} \mathrm{C} / \mathrm{min}$ in air using a DTGA-60 Shimadzu (Shimadzu, Kyoto, Japan) automatic analyzer.

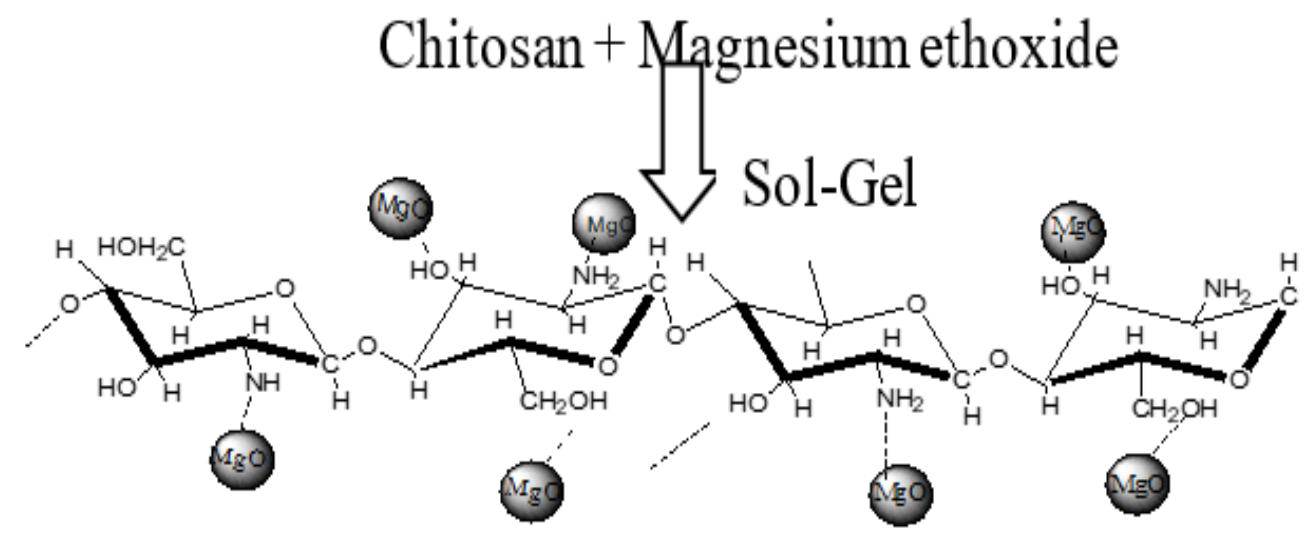

Scheme 1. Chitosan-Magnesium nanoparticle hybrid film.

\subsection{General Procedure for Synthesis of Pyrimidine Derivatives}

A mixture of aldehyde $(10 \mathrm{mmol})$, guanidine hydrochloride $(0.95 \mathrm{~g}, 10 \mathrm{mmol})$, malononitrile or ethyl cyanoacetate $(10 \mathrm{mmol})$ and CS-MgO nanocomposite films (5 and $10 \% \mathrm{MgO}$ content) was dispersed in $10 \mathrm{~mL}$ of the selected solvent (See tables). The suspension was heated using microwave irradiation $(100 \mathrm{~W})$ for the appropriate amount of time (monitored by TLC (Silver Spring, Maryland) using 1:1 n-hexane/ethyl acetate as eluent). After completion, the film was removed from the hot mixture and was then washed thoroughly with hot methanol, using the simple Soxhlet method. The remaining mixture was then concentrated and poured into an ice/water mixture. The crude solid that formed was separated through filtration and then crystallized using hot ethanol. The previous method was repeated under the same employed conditions but in the presence of a catalytic amount of $\mathrm{MgO}$ nanoparticles (5 wt.\%) in order to compare the potency of our nanocomposite to that of the $\mathrm{MgO}$ nanoparticles.

\subsection{General Procedure for Synthesis of Benzochromene Derivatives}

A mixture of the aldehyde (10 mmol), 1-naphthol $(1.44 \mathrm{~g}, 10 \mathrm{mmol})$, malononitrile ( $0.66 \mathrm{~g}, 10 \mathrm{mmol}$ ) and CS-MgO nanocomposite films (5 and 10\% MgO content) was dispersed in $10 \mathrm{~mL}$ of the selected solvent. The mixture was heated using microwave irradiation $(100 \mathrm{~W})$ for the appropriate amount of time (monitored by TLC using 1:1 nhexane/ethyl acetate as eluent). After the completion of the reaction, the film was removed, and the crude solid product was separated through filtration and crystallized from ethanol. Similarly, the previous method was repeated under the same employed conditions with the presence of $\mathrm{MgO}$ nanoparticles (5 wt.\%) for comparison.

\subsection{General Procedure for Synthesis of Coumarin Derivatives}

A mixture of salicylaldehyde $(1.22 \mathrm{~g}, 10 \mathrm{mmol})$, the active methylene compounds (10 mmol), and the CS-MgO nanocomposite film (5 and 10\% MgO content) were mixed in $10 \mathrm{~mL}$ of the appropriate solvent. The mixture was heated using microwave irradiation $(100 \mathrm{~W})$ for the appropriate amount of time (monitored by TLC using 1:1 n-hexane/ethyl acetate as eluent). After the completion of the reaction, the film was removed, and the filtrate was concentrated. The residue was added to ice/water, producing a precipitate 
that was separated through filtration and crystallized from ethanol. This method was also repeated under the same employed conditions with the presence of $\mathrm{MgO}$ nanoparticles (5 wt.\%) for comparison.

\subsection{General Procedure for Synthesis of Heterocyclic Arylidene-Malononitriles}

A mixture of furfural, thiophene-2-carboxaldehyde or pyridine-4-carboxaldehyde (10 mmol), malononitrile $(0.66 \mathrm{~g}, 10 \mathrm{mmol})$ and CS-MgO nanocomposite films (5 and $10 \% \mathrm{MgO}$ content) was heated using microwave irradiation $(100 \mathrm{~W})$ for $1 \mathrm{~min}$. After the completion of the reaction, the film was removed through simple filtration. The crude solid product was separated by adding hot methanol followed by filtration and then crystallized from ethanol. The procedure was repeated under the same conditions but in the presence of $\mathrm{MgO}$ nanoparticles ( $5 \mathrm{wt} . \%$ ) for comparison.

\section{Results and Discussion}

\subsection{Characterization of Chitosan-Mgo Nanocomposite Films}

\subsubsection{Microscopic Analysis}

FESEM was used to assess the morphology and size distribution of the $\mathrm{MgO}$ nanoparticles in the polymer matrix. FESEM micrographs of pure chitosan (Figure 1A) and hybrid films containing magnesia particles of $5 \mathrm{wt} . \%$ (Figure 1B) and $10 \mathrm{wt} . \%$ are shown in Figure 1C. An inspection of the micrographs reveals that the surface of the pure chitosan is homogenous, continuous, and smooth. The $\mathrm{MgO}$ nanoparticles in the chitosan- $\mathrm{MgO}$ nanocomposite are visible in the form of clouds distributed in the polymer matrix. The nanoparticles appear as dense phases that resemble white spherical beads with somewhat dispersed surfaces. The blurred surfaces are a consequence of adsorption of the polymer layers on the particles surface. The images show that the inorganic phase is well dispersed in the chitosan matrix. The average size of the $\mathrm{MgO}$ nanoparticles in the $5 \mathrm{wt} . \%$ loading is approximately $\sim 14 \mathrm{~nm}$ while it is $\sim 11 \mathrm{~nm}$ for $10 \mathrm{wt} . \%$ loading which is comparable with the crystallite size of $10.7 \mathrm{~nm}$ calculated from XRD pattern (not shown).
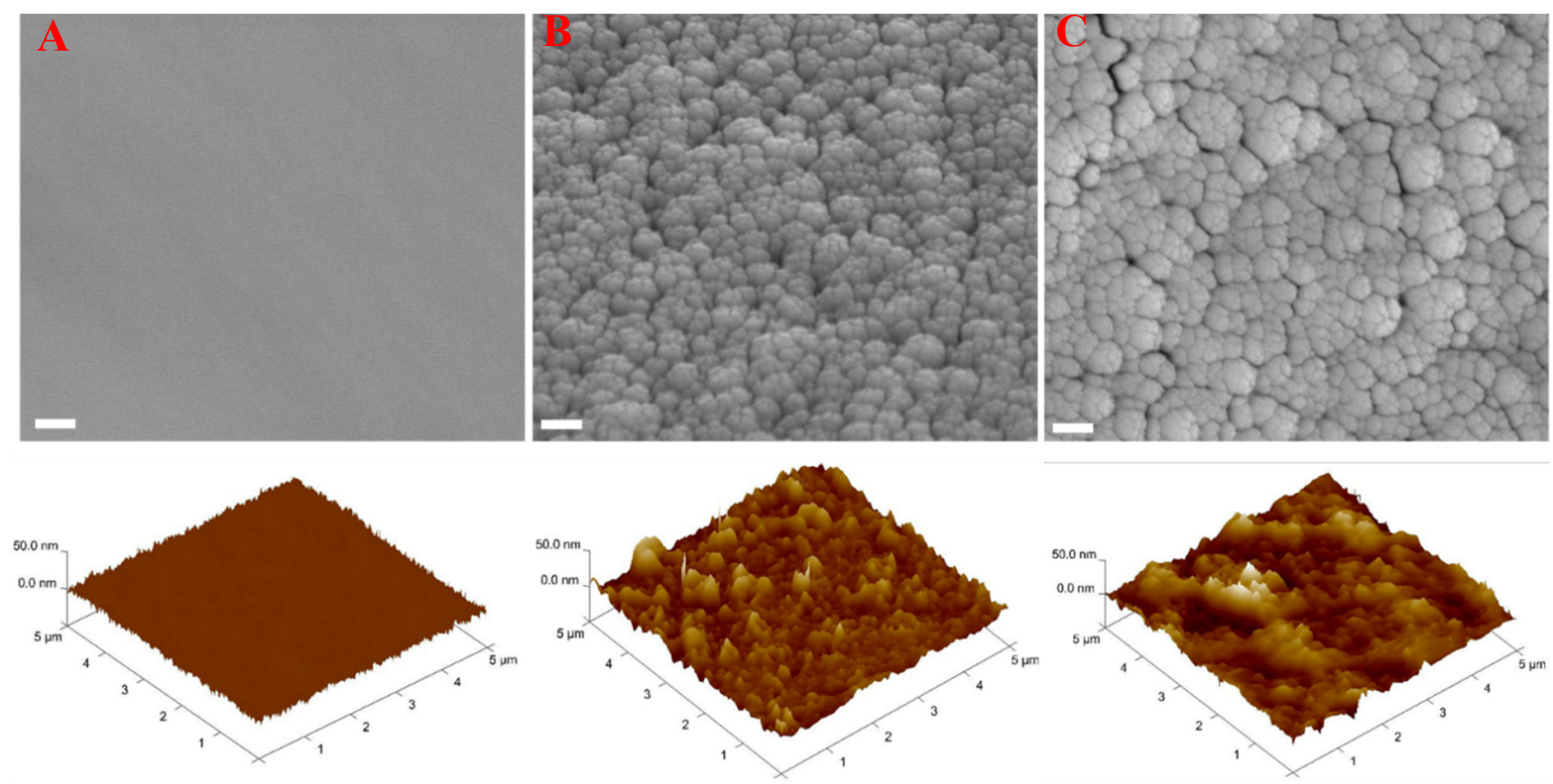

Figure 1. FESEM and AFM images of (A) Chitosan, (B) Chitosan-MgO 5 wt.\% and (C) chitosan-MgO 10 wt.\%. The scale bare for FESEM is $100 \mathrm{~nm}$. 
Furthermore, AFM was used to study the surface topology of the $\mathrm{MgO} /$ chitosan nanocomposite composite films and to assess the roughness and uniformity of dispersions of $\mathrm{MgO}$ in the polymer matrix. An inspection of the three-dimensional AFM images displayed in Figure 1 shows that the pure chitosan film has a smooth and flat textured surface indicating the absence of observable agglomerates (Figure 1A). In Figure 1B,C AFM images are shown from $5 \mathrm{wt} . \%$ and $10 \mathrm{wt} . \%$ of magnesia composite films, respectively. The surfaces of the hybrids have globular rough morphologies with some needles lying on the surface, most of which are oriented perpendicular to the surface. This observation indicates that the $\mathrm{MgO}$ nanoparticles are uniformly distributed in the chitosan matrix. As the magnesia content increases, the interactions of $\mathrm{MgO}$ with the polymer increases and the particles become well distributed and completely cover the polymer. The image of the hybrid is blurred because the densely distributed particles are engulfed by the polymer chains (Figure 1C).

\subsubsection{XPS Analysis}

X-ray photoelectron spectroscopy (XPS) was utilized to investigate the surface elemental composition of the CS-MgO hybrid films. The binding energies of the elements in the chitosan/magnesia hybrid film, obtained from an analysis of the resolved XPS spectrum, for C1s (A), and O1s (B), N1s (C) and Mg1s (D) are provided in Figure 2. The peaks in the spectrum for C1s correspond to C-C/C-H (284.6 eV), C-O (286.2) and C $=\mathrm{O}(288.0 \mathrm{eV})$, the latter being attributed to acetyl groups on the chitosan backbone [26]. The results show that carbon, oxygen, nitrogen, and magnesium are present in the hybrid film. Two peaks exist in the $\mathrm{O} 1 \mathrm{~s}$ spectrum, and the peak at $531.5 \mathrm{eV}$ is attributed to $\mathrm{N}-\mathrm{C}-\mathrm{O}$ chemical binding in $\mathrm{N}$-acetylated-glucosamine units and the other peak, at $532.7 \mathrm{eV}$, is assigned to $\mathrm{C}-\mathrm{O}, \mathrm{O}-\mathrm{H}$ or bound water $[27,28]$. The N1s XPs spectrum of the chitosan/magnesia nanocomposite film contains a peak at $399.1 \mathrm{eV}$ that is attributed to the $\mathrm{NH}_{2}$ or $\mathrm{NH}$ groups and another at $400.0 \mathrm{eV}$ is associated with the amine groups in the ammonium form $\left(\mathrm{NH}_{3}{ }^{+}\right)$[29]. The $\mathrm{N}$ peaks in the hybrid appear at lower binding energies compared to those of the pristine chitosan (399.1 and 400.0) [30], which indicates that the amine groups interact with $\mathrm{MgO}$ nanoparticles. The binding energy of $\mathrm{Mg} 1 \mathrm{~s}$ at $1304.5 \mathrm{eV}$ is attributed to the $\mathrm{Mg}^{2+}$ in MgO nanoparticles [31].

\subsubsection{Thermogravimetric Analysis}

A thermal analysis was performed to assess the material $\| \mathrm{s}$ stability as a function of temperature to gain an understanding of their degradation behavior. The thermogravimetric analysis was performed using the sample under air in the temperature range of $30-800{ }^{\circ} \mathrm{C}$. Figure 3 presents the weight loss versus temperature profile of pure chitosan (A) and of the hybrid materials with $5 \mathrm{wt} . \%$ (B) and $10 \mathrm{wt} . \%$ (C) of magnesia. The initial weight reduction, occurring prior $150^{\circ} \mathrm{C}$, is a consequence of moisture loss. This is followed by a degradation with a loss of the carboxylic and hydroxyl groups in the chitosan between $170-450^{\circ} \mathrm{C}$. The thermal decomposition temperatures of the hybrid materials are around $480^{\circ} \mathrm{C}$. The results show that the hybrid films are more thermally stable than the pure polymer because of the presence of magnesium oxide. Moreover, the stability of the hybrid increases as the content of $\mathrm{MgO}$ increases. The mass of the remaining residue after treatment at $800{ }^{\circ} \mathrm{C}$ corresponds to the magnesium oxide content of the hybrids, indicating that the sol-gel reaction was successful. 


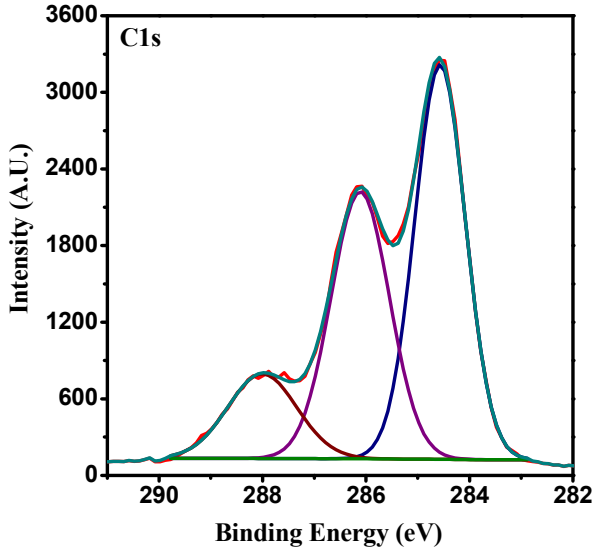

(A)

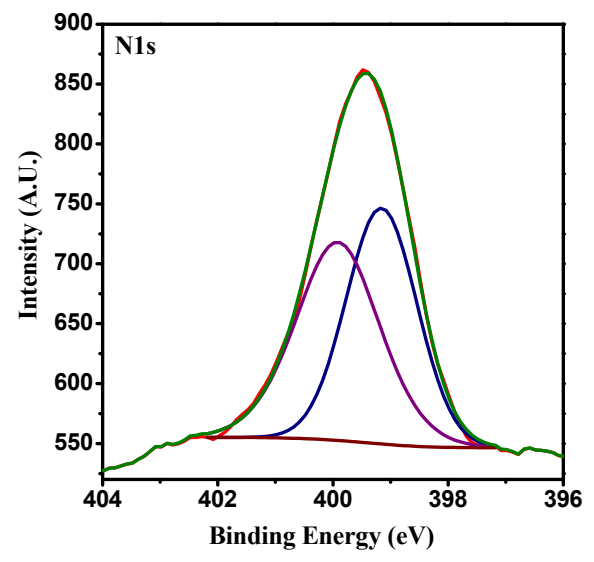

(C)

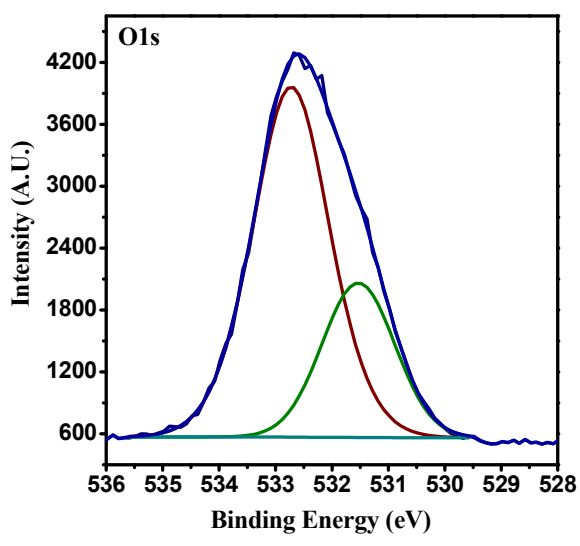

(B)

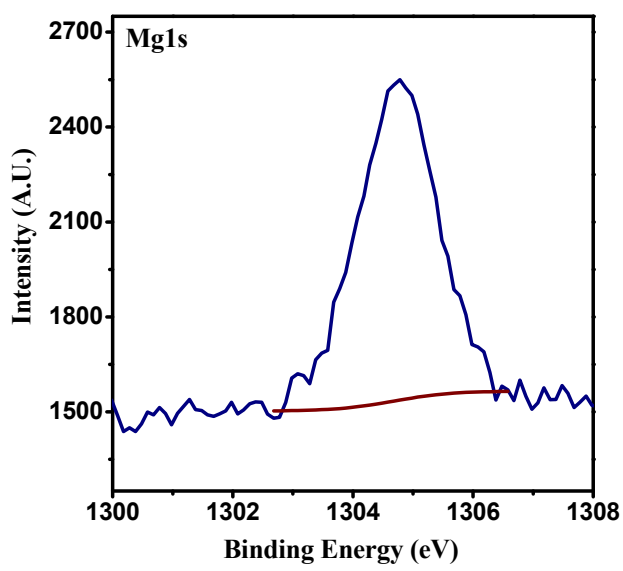

(D)

Figure 2. XPS binding energies 10 wt.\% magnesia / chitosan hybrid film, spectra of C1s peak (A), O1s peak (B), N1s peak (C), Mg1s peak (D).

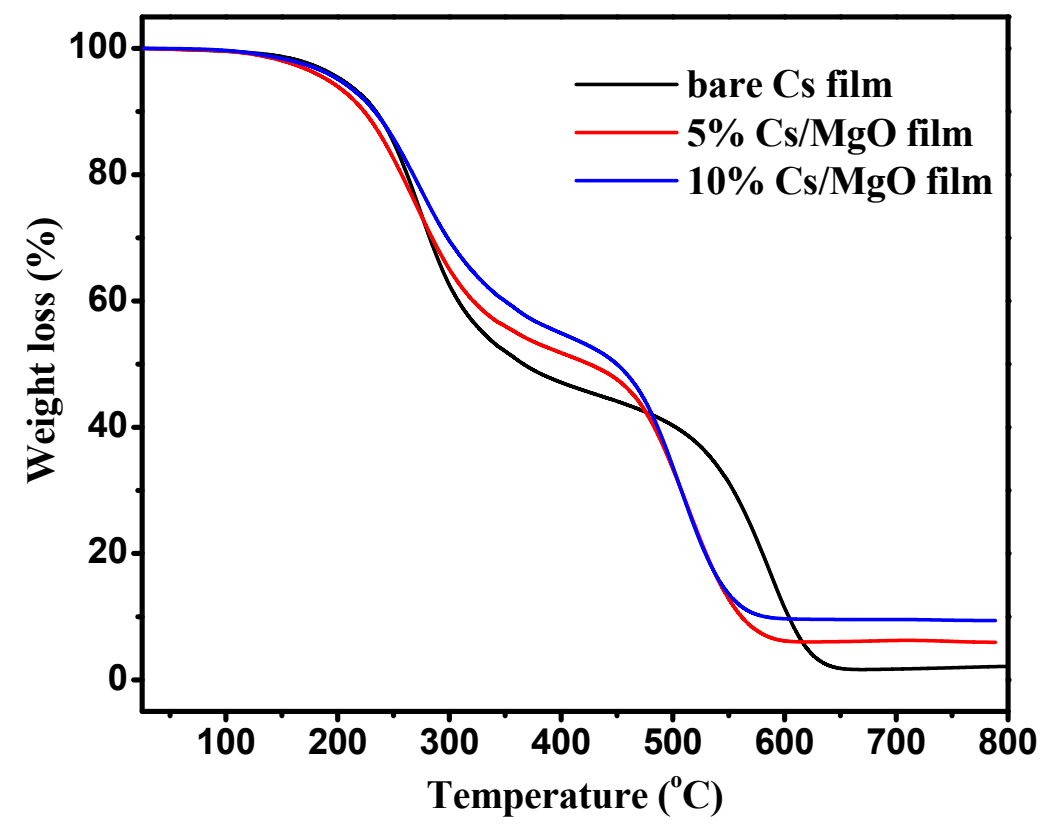

Figure 3. TGA of bare chitosan, 5 wt. $\%$ chitosan $/ \mathrm{MgO}$ and $10 \mathrm{wt} . \%$ Chitosan-MgO films. 


\subsection{Application of the CS-Mgo Nanocomposite Films As Heterogeneous Basic Catalyst}

The reactions of aromatic aldehydes with guanidine hydrochloride and malononitrile, which are promoted by basic catalysts, have been found to produce pyrimidine5-carbonitriles 1 . To investigate the catalytic activity of CS-MgO films and to optimize the reaction conditions, a preliminary study was conducted to probe the synthesis of pyrimidine derivatives through condensation reactions between benzaldehyde, guanidine hydrochloride and malononitrile in dry acetonitrile, which was promoted using different $\mathrm{MgO}$ loadings of the CS-MgO film catalyst (0, 5, 10, 20 and $30 \mathrm{wt} . \%)$. The results of this exploratory investigation demonstrate that a catalyst loading of $10 \mathrm{wt} . \%$ is optimal and that the process proceeds efficiently when using microwave irradiation $(100 \mathrm{~W})$ at $60{ }^{\circ} \mathrm{C}$ for 2 min (Figure 4). Moreover, we found that the used catalyst can be recovered; the used catalyst was thereafter subjected to an extensive washing process with hot ethanol via Soxhlet extraction for $1 \mathrm{~h}$ and reused four times without a significant loss of its catalytic activity (Figure 5).

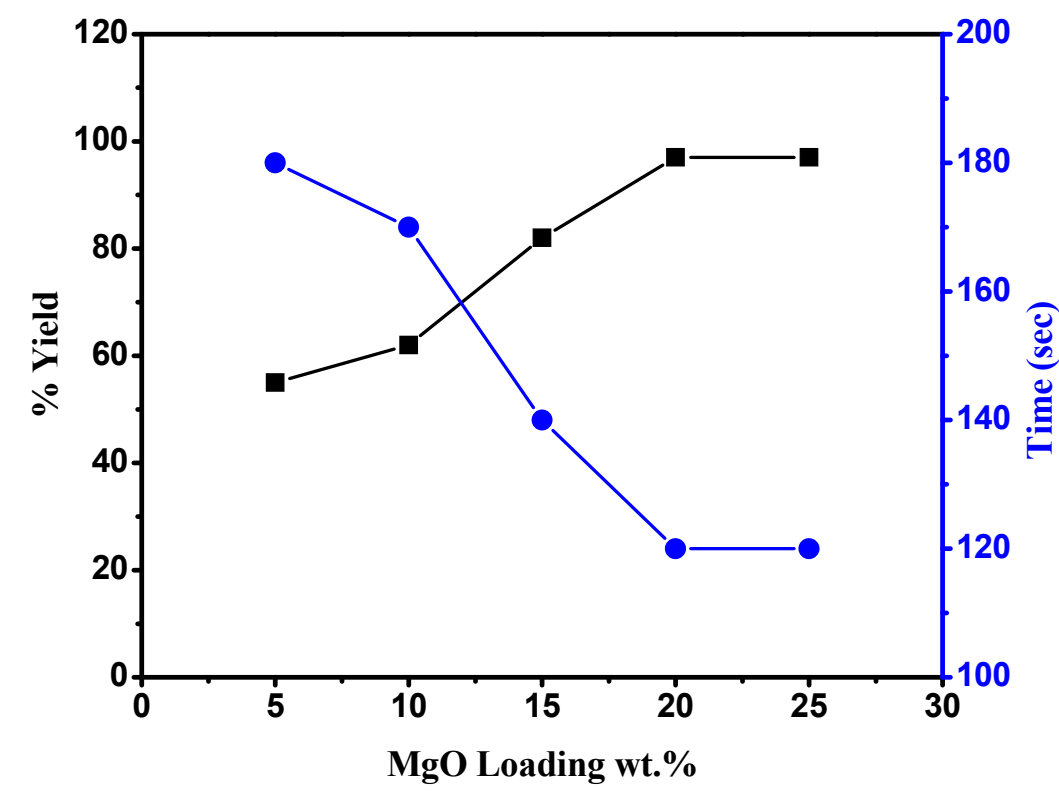

Figure 4. Optimization of the loading of CS-MgO film as a basic catalyst.

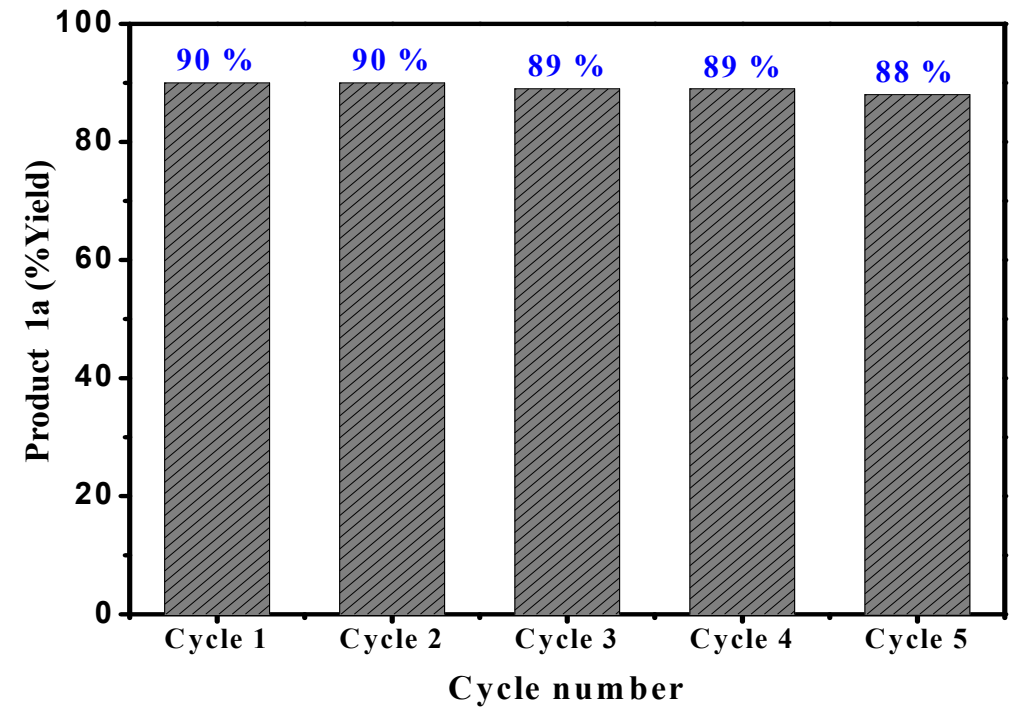

Figure 5. Recyclability of the CS-MgO film as a basic catalyst. 
In contrast to earlier observations [32,33], we found that the reaction promoted by $10 \mathrm{wt}$ \% of CS-MgO film produced 2,4-diaminopyrimidine-5-carbonitriles 1 in an excellent yield $(97 \%)$ (Scheme 2$)$. The preliminary experiments confirmed that dry acetonitrile is the ideal solvent for the reaction. Due to the fact that the separation and contamination of products with $\mathrm{MgO}$ nanoparticles presents a considerable challenge, the investigated catalytic reactions were repeated under the same employed conditions in the presence of a catalytic amount of $\mathrm{MgO}$ nanoparticles (5 wt.\%) for comparison. The results revealed that a synergistic action occurs for the combination of chitosan and $\mathrm{MgO}$ nanoparticles confirming that the hybrid materials work as more of a base catalyst compared to its constituent components. Thus, in a study evaluating other catalysts for this one pot reaction, stirring the mixtures of the reactants in the presence of chitosan CS powder, nano-sized $\mathrm{MgO}$ powder or CS-MgO film at reflux can lead to the formation of $\mathbf{1}$ in the following order of yields CS-MgO $>\mathrm{MgO}>\mathrm{CS}$.<smiles>O=CBr</smiles><smiles>N=C(N)N</smiles>

Guanidine. $\mathrm{H} \mathrm{Cl}$<smiles>N#CCC#N</smiles>

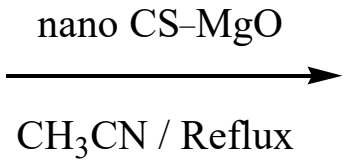<smiles>N#Cc1c(N)nc(N)nc1Br</smiles>

$$
\begin{aligned}
& \text { 1a-c } \\
& \mathrm{a}=\mathrm{C}_{6} \mathrm{H}_{5}^{-} \\
& \mathrm{b}=4-\mathrm{Cl}-\mathrm{C}_{6} \mathrm{H}_{4}- \\
& \mathrm{c}=4-\mathrm{MeO}-\mathrm{C}_{6} \mathrm{H}_{4}-
\end{aligned}
$$

Scheme 2. CS-MgO (10 wt.\%) catalyzed reactions forming 2,4-diaminopyrimidine-5-carbonitriles.

A variety of substrate solvents of different polarity were employed to investigate the scope of the CS-MgO catalyzed one pot reaction in generating 2,4-diaminopyrimidine-5carbonitriles (Table 1). The overall results of the investigation described above revealed that CS-MgO serves as an efficient basic catalyst for classical one-pot Knoevenagel reactions. In order to investigate the catalytic activity of the CS-MgO catalyst in the one pot synthesis of 2,6-diaminopyrimidine-5-carbonitriles and to optimize the reaction conditions, a study was conducted using different substrates, various solvents of different polarity, and under solvent free conditions (Table 1).

A similar process involving benzaldehyde, guanidine hydrochloride and ethyl cyanoacetate and the CS-MgO nano-catalyst (in comparison to the $\mathrm{MgO}$ nanoparticles) was observed, producing 6-oxo-pyrimidine-5-carbonitrile derivatives in relatively high yields (Scheme 3). The products of these reactions were shown to have keto structures by using NMR spectroscopy (Performed in NMR-600 Bruker) and mass spectrometry (Performed in GCms-DFS-Thermo). Although it is in disagreement with an earlier proposal [34] we found that the hydroxypyrimidine products do not exist in a solution in their enol forms. This conclusion is consistent with the observation of characteristic signals at $11.8 \mathrm{ppm}$ in the ${ }^{1} \mathrm{H}$ NMR spectra, which evidences the presence of lactam NH groups. Finally, a brief study was conducted to compare the catalytic activity of CS-MgO to that of $\mathrm{MgO}$ (Table 2). Further, the results revealed a higher catalytic effect for the hybrid nanocomposite compared with the use of $\mathrm{MgO}$ nanoparticles alone. 
Table 1. Data comparing catalysts and solvent for one pot reaction forming diaminopyrimidine-5-carbonitriles (Scheme 2).

\begin{tabular}{|c|c|c|c|c|c|c|}
\hline No. & Product 1 & Ar & Solvent & m.p. $\left({ }^{\circ} \mathrm{C}\right)$ & $\begin{array}{c}\text { MgO } \\
\text { \%Yield }\end{array}$ & $\begin{array}{l}\text { CS-MgO } \\
\text { \% Yield }\end{array}$ \\
\hline 1 & $1 \mathrm{a}$ & $\mathrm{C}_{6} \mathrm{H}_{5}-$ & $\mathrm{EtOH} / \mathrm{H}_{2} \mathrm{O}$ & $234-23$ [31] & 70 & 80 \\
\hline 2 & $1 \mathrm{a}$ & $\mathrm{C}_{6} \mathrm{H}_{5-}^{-}$ & $\mathrm{MeOH}$ & & 78 & 85 \\
\hline 3 & $1 \mathrm{a}$ & $\mathrm{C}_{6} \mathrm{H}_{5}-$ & $\mathrm{MeCN}$ & & - & 92 \\
\hline 4 & $1 \mathrm{a}$ & $\mathrm{C}_{6} \mathrm{H}_{5}-$ & Solvent free & & - & 68 \\
\hline 5 & $1 b$ & $4-\mathrm{Cl}-\mathrm{C}_{6} \mathrm{H}_{4}-$ & $\mathrm{EtOH} / \mathrm{H}_{2} \mathrm{O}$ & 233 [31] & 65 & 70 \\
\hline 6 & $1 b$ & $4-\mathrm{Cl}-\mathrm{C}_{6} \mathrm{H}_{4}-$ & $\mathrm{MeOH}$ & & 72 & 75 \\
\hline 7 & $1 b$ & $4-\mathrm{Cl}-\mathrm{C}_{6} \mathrm{H}_{4}-$ & $\mathrm{MeCN}$ & & - & 97 \\
\hline 8 & $1 b$ & $4-\mathrm{Cl}-\mathrm{C}_{6} \mathrm{H}_{4}-$ & Solvent free & & - & 78 \\
\hline 9 & 1c & $4-\mathrm{MeO}-\mathrm{C}_{6} \mathrm{H}_{4}-$ & $\mathrm{EtOH} / \mathrm{H}_{2} \mathrm{O}$ & 238 [32] & 72 & 80 \\
\hline 10 & $1 c$ & $4-\mathrm{MeO}-\mathrm{C}_{6} \mathrm{H}_{4}-$ & $\mathrm{MeOH}$ & & 85 & 90 \\
\hline 11 & $1 c$ & $4-\mathrm{MeO}-\mathrm{C}_{6} \mathrm{H}_{4}^{-}$ & $\mathrm{MeCN}$ & & - & 90 \\
\hline 12 & $1 c$ & $4-\mathrm{MeO}-\mathrm{C}_{6} \mathrm{H}_{4}^{-}$ & Solvent free & & - & 85 \\
\hline
\end{tabular}

Table 2. Data comparing the catalysts and solvents for one pot reaction forming 6-oxopyrimidine-5-carbonitriles (Scheme 3).

\begin{tabular}{|c|c|c|c|c|c|c|}
\hline No. & Product 2 & Ar & Solvent & m.p. $\left({ }^{\circ} \mathrm{C}\right)$ & $\begin{array}{c}\text { MgO } \\
\% \text { Yield }\end{array}$ & $\begin{array}{l}\text { CS-MgO } \\
\text { \% Yield }\end{array}$ \\
\hline 1 & $2 a$ & $\mathrm{C}_{6} \mathrm{H}_{5}-$ & $\mathrm{EtOH} / \mathrm{H}_{2} \mathrm{O}$ & $242-243$ & 70 & 74 \\
\hline 2 & $2 a$ & $\mathrm{C}_{6} \mathrm{H}_{5}-$ & $\mathrm{MeOH}$ & & 74 & 81 \\
\hline 3 & $2 a$ & $\mathrm{C}_{6} \mathrm{H}_{5}-$ & $\mathrm{MeCN}$ & & - & 78 \\
\hline 4 & $2 a$ & $\mathrm{C}_{6} \mathrm{H}_{5}^{-}$ & Solvent free & & - & 69 \\
\hline 5 & $2 b$ & $4-\mathrm{Cl}-\mathrm{C}_{6} \mathrm{H}_{4}-$ & $\mathrm{EtOH} / \mathrm{H}_{2} \mathrm{O}$ & 248-250 [35] & 60 & 62 \\
\hline 6 & $2 b$ & $4-\mathrm{Cl}-\mathrm{C}_{6} \mathrm{H}_{4}-$ & $\mathrm{MeOH}$ & & 66 & 68 \\
\hline 7 & $2 b$ & $4-\mathrm{Cl}-\mathrm{C}_{6} \mathrm{H}_{4}-$ & $\mathrm{MeCN}$ & & - & 69 \\
\hline 8 & $2 b$ & $4-\mathrm{Cl}-\mathrm{C}_{6} \mathrm{H}_{4}-$ & Solvent free & & - & 57 \\
\hline 9 & $2 c$ & $4-\mathrm{NO}_{2}-\mathrm{C}_{6} \mathrm{H}_{4}-$ & $\mathrm{EtOH} / \mathrm{H}_{2} \mathrm{O}$ & $223-224$ [34] & 74 & 75 \\
\hline 10 & $2 c$ & $4-\mathrm{NO}_{2}-\mathrm{C}_{6} \mathrm{H}_{4}-$ & $\mathrm{MeOH}$ & & 80 & 84 \\
\hline 11 & $2 c$ & $4-\mathrm{NO}_{2}-\mathrm{C}_{6} \mathrm{H}_{4}-$ & $\mathrm{MeCN}$ & & - & 85 \\
\hline 12 & $2 c$ & $4-\mathrm{NO}_{2}-\mathrm{C}_{6} \mathrm{H}_{4}-$ & Solvent free & & - & 75 \\
\hline 13 & $2 d$ & $4-\mathrm{NC}-\mathrm{C}_{6} \mathrm{H}_{4}-$ & $\mathrm{EtOH} / \mathrm{H}_{2} \mathrm{O}$ & $357-358$ & 69 & 69 \\
\hline 14 & $2 d$ & $4-\mathrm{NC}-\mathrm{C}_{6} \mathrm{H}_{4}-$ & $\mathrm{MeOH}$ & & 78 & 82 \\
\hline 15 & $2 d$ & $4-\mathrm{NC}-\mathrm{C}_{6} \mathrm{H}_{4}-$ & $\mathrm{MeCN}$ & & - & 86 \\
\hline 16 & $2 d$ & $4-\mathrm{NC}-\mathrm{C}_{6} \mathrm{H}_{4}-$ & Solvent free & & - & 77 \\
\hline
\end{tabular}<smiles>O=CBr</smiles><smiles>N=C(N)N</smiles>

Guanidine. $\mathrm{H} \mathrm{Cl}$

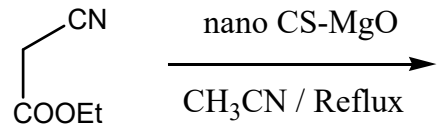<smiles>N#Cc1c(Br)nc(N)[nH]c1=O</smiles>

2a-d

$\mathrm{a}=\mathrm{C}_{6} \mathrm{H}_{5}$ $\mathrm{b}=4-\mathrm{Cl}-\mathrm{C}_{6} \mathrm{H}_{4}-$ $\mathrm{c}=4-\mathrm{NO}_{2}-\mathrm{C}_{6} \mathrm{H}_{4}-$ $\mathrm{d}=4-\mathrm{NC}-\mathrm{C}_{6} \mathrm{H}_{4}-$

Scheme 3. CS-MgO (10 wt.\%) catalyzed reaction forming 6-oxopyrimidine-5-carbonitriles. 
A plausible mechanism for the 2,4-diaminopyrimidine-5-carbonitrile forming reaction follows involves the initial generation of arylidene-malononitrile via deprotonation of malononitrile by the CS-MgO catalyst (in comparison to the $\mathrm{MgO}$ nanoparticles) and the addition of the enolate to the aldehyde. The arylidene-malononitrile produced in this manner undergoes a Michael addition with guanidine, which is generated from the salt precursor by proton transfer to the basic catalyst. The process ends by a route proceeding through the intermediate A or B and the generate 1a (Scheme 4).

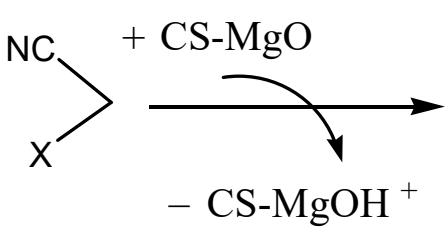

$\mathrm{X}=\mathrm{CN}, \mathrm{COOEt}$
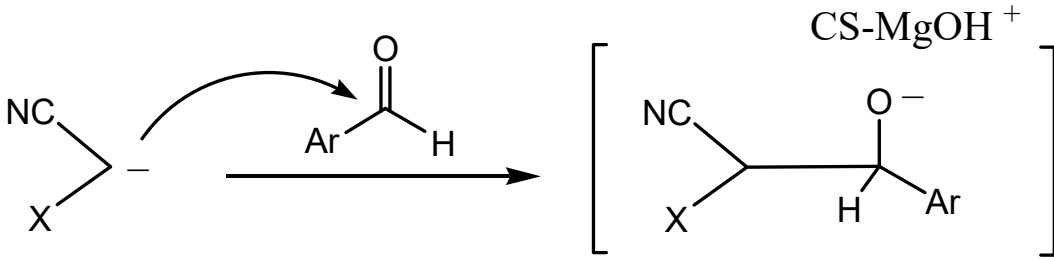<smiles>C[As](C)(C)[Mg]</smiles><smiles>[X]C(C)=C[Bi]</smiles>

Arylidine<smiles>N#CC(C#N)=C[Bi]</smiles>

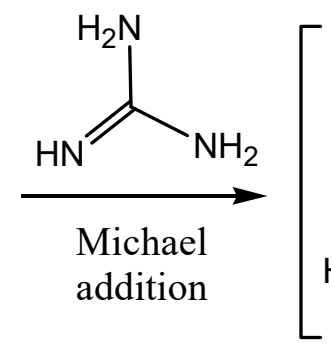<smiles>N#CC1C(=N)NC(=N)NC1Br</smiles>

A<smiles>N#Cc1c(N)nc(N)nc1Br</smiles><smiles>CCOC(=O)/C(C#N)=C/Br</smiles><smiles>N=C(N)N</smiles><smiles>N#CC1C(=O)NC(=N)NC1Br</smiles><smiles>N#Cc1c(Br)nc(N)[nH]c1=O</smiles>

$-\mathrm{EtOH}$

B

Scheme 4. Proposed mechanism of CS-MgO (10 wt.\%) catalyzed Michael addition reactions. 
The scope and limitations of the one-pot multicomponent reactions, promoted by the CS-MgO nano-sized catalyst (also in comparison with the $\mathrm{MgO}$ nanoparticles), were explored for this purpose and the multicomponent reactions of malononitrile, aromatic aldehydes, and $\alpha$-naphthol were conducted using the conditions presented in Scheme 5 and Table 3. As the data in Table 3 presents, these reactions produce pyrimidone-5carbonitriles. Again, the results presented the higher catalytic potency of the CS-MgO hybrid nanocomposite to be an excellent promoter for the investigated reactions.

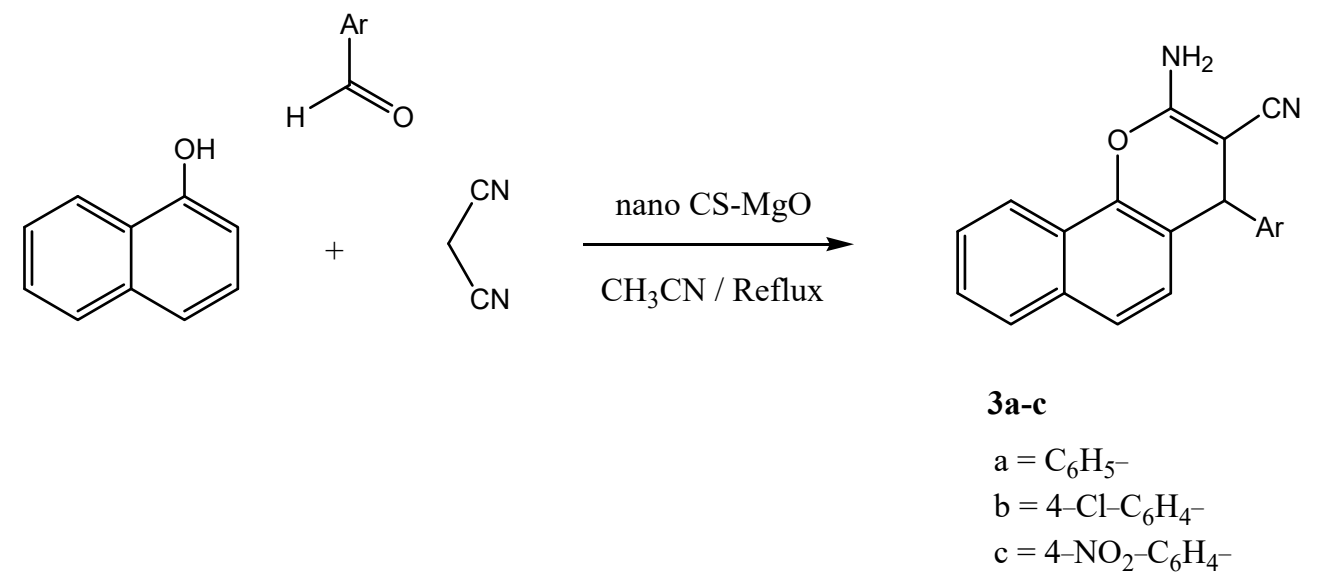

Scheme 5. CS-MgO (10 wt.\%) catalyzed reactions forming pyrimidone-5-carbonitriles.

Table 3. Data comparing catalysts and solvents for one pot reactions forming f 2-amino-4-aryl-4H-benzo[h]chromene-3carbonitrile (Scheme 5).

\begin{tabular}{|c|c|c|c|c|c|c|c|}
\hline \multirow{2}{*}{$\begin{array}{c}\text { No. } \\
1\end{array}$} & \multirow{2}{*}{$\begin{array}{c}\text { Product } 3 \\
3 a\end{array}$} & \multirow{2}{*}{$\begin{array}{c}\mathrm{Ar} \\
\mathrm{C}_{6} \mathrm{H}_{5}-\end{array}$} & \multirow{2}{*}{$\begin{array}{c}\text { Solvent } \\
\text { EtOH }\end{array}$} & \multicolumn{2}{|c|}{$\begin{array}{l}\text { m.p. }\left({ }^{\circ} \mathrm{C}\right) \\
\text { obs. Lit. }\end{array}$} & \multirow{2}{*}{$\begin{array}{c}\begin{array}{c}\text { MgO } \\
\text { \%Yield }\end{array} \\
70\end{array}$} & \multirow{2}{*}{$\begin{array}{c}\text { CS-MgO } \\
\text { \% Yield }\end{array}$} \\
\hline & & & & 218 & 218-219 [36] & & \\
\hline 2 & $3 a$ & $\mathrm{C}_{6} \mathrm{H}_{5}-$ & $\mathrm{EtOH} / \mathrm{H}_{2} \mathrm{O}$ & & & 75 & 78 \\
\hline 3 & $3 a$ & $\mathrm{C}_{6} \mathrm{H}_{5}^{-}$ & Solvent free & & & - & 71 \\
\hline 4 & $3 b$ & $4-\mathrm{Cl}-\mathrm{C}_{6} \mathrm{H}_{4}-$ & $\mathrm{EtOH}$ & $231-232$ & $232-233$ [36] & 78 & 84 \\
\hline 5 & $3 b$ & $4-\mathrm{Cl}-\mathrm{C}_{6} \mathrm{H}_{4}-$ & $\mathrm{EtOH} / \mathrm{H}_{2} \mathrm{O}$ & & & 88 & 92 \\
\hline 6 & $3 b$ & $4-\mathrm{Cl}-\mathrm{C}_{6} \mathrm{H}_{4}-$ & Solvent free & & & - & 78 \\
\hline 7 & $3 c$ & $4-\mathrm{NO}_{2}-\mathrm{C}_{6} \mathrm{H}_{4}-$ & $\mathrm{EtOH}$ & 184 & 184-185 [37] & 70 & 74 \\
\hline 8 & $3 c$ & $4-\mathrm{NO}_{2}-\mathrm{C}_{6} \mathrm{H}_{4}-$ & $\mathrm{EtOH} / \mathrm{H}_{2} \mathrm{O}$ & & & 76 & 78 \\
\hline 9 & $3 c$ & $4-\mathrm{NO}_{2}-\mathrm{C}_{6} \mathrm{H}_{4}-$ & Solvent free & & & - & 67 \\
\hline
\end{tabular}

Interestingly, the reaction of aromatic aldehydes, containing electron-donating substituents, occurs in relatively higher yields than those with electron-withdrawing groups. An attempt was made to utilize the CS-MgO nano-catalyst to promote arylidene-malononitrile forming reactions of pyridine-2-carboxaldehyde, furfural and thiophene-2-carboxaldehyde (Scheme 6). These reactions, conducted using malononitrile in the presence of the optimized amount $(10 \mathrm{wt} . \%)$ of the catalyst using microwave irradiation $(100 \mathrm{~W})$ at $60^{\circ} \mathrm{C}$ for $1 \mathrm{~min}$, generated the corresponding products in higher yields $(85 \%, 92 \%$ and $98 \%$, respectively) than those previously reported by Bobal et al. [38] using piperidine as the base (53\%, $72 \%$, and $78 \%$ respectively). Again, it is worthwhile to mention that CS-MgO can be easily recovered from the reaction mixture and recycled up to four times without a significant loss of its catalytic activity. Also, the stability of the recovered catalyst was confirmed by comparing its IR spectra before and after the catalytic reaction. 


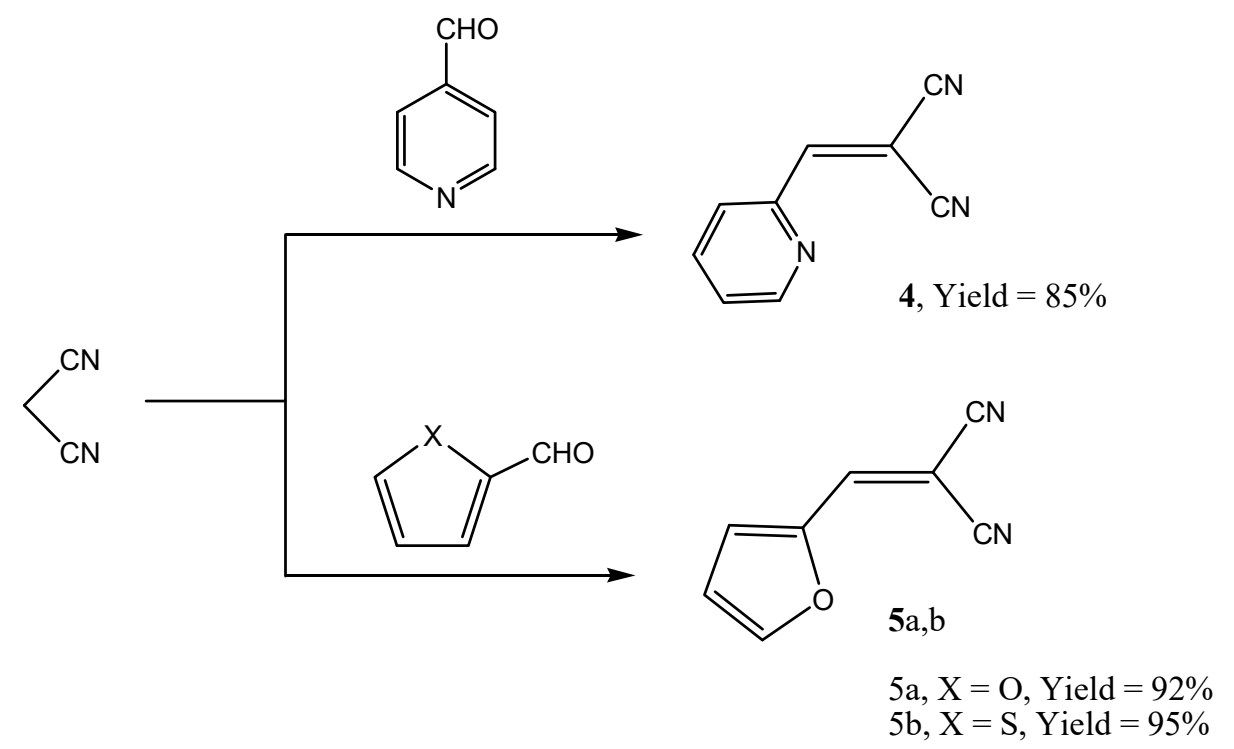

Scheme 6. CS-MgO (10 wt.\%) catalyzed reactions forming heteroaromatic arylidene-malononitrile.

\section{Conclusions}

Chitosan-MgO hybrid films were prepared using the sol-gel process. The results of this investigation demonstrate that a CS-Mg hybrid film was an efficient candidate as a basic, recyclable, and environmentally friendly heterogeneous catalyst for Michael addition reactions. Furthermore, preliminary studies suggested that CS-MgO (10 wt.\%) nanocomposite films can be used as an efficient catalyst for Michael additions compared with bare chitosan and $\mathrm{MgO}$ nanoparticles. Moreover, the CS-MgO heterogeneous catalyst film can be easily recovered from the reaction mixture and can be recycled up to four times without a considerable loss of its catalytic activity. Thus, this new basic catalyst can be used as a potential alternative to other more toxic organic catalysts for Michael addition reactions such as piperidine and pyridine. In addition, the hybrid nanocomposite film presented a higher thermal stability than chitosan and, therefore, can be effectively utilized for high-temperature reactions.

Author Contributions: Conceptualization, F.A.A., and K.D.K.; Data curation, F.A.A., and K.D.K.; Formal analysis, F.A.A., and K.D.K.; Investigation, F.A.A., and K.D.K.; Methodology, K.D.K.; Resources, F.A.A.; Supervision, F.A.A., M. M., and K.D.K.; Writing-original draft, K.D.K., and F.A.A.; Writing-review and editing, K.D.K., M.M., and F.A.A. All authors have read and agreed to the published version of the manuscript.

Funding: Kuwait University- Research Administration.

Institutional Review Board Statement: Not applicable.

Informed Consent Statement: Not applicable.

Data Availability Statement: The data presented in this study are available on request from the corresponding author.

Acknowledgments: The authors acknowledge the support of Research Administration at Kuwait University through RSPU unit general facilities projects GS01/01, GS01/03, GS01/05, GS03/01. Also, the authors acknowledge the Nanoscopy Science Centre at Faculty of Science for FESEM and AFM imaging.

Conflicts of Interest: The authors declare no conflict of interest. 


\section{References}

1. Khalil, K.D.; Ibrahim, E.I.; Al-Sagheer, F.A. A novel, efficient, and recyclable biocatalyst for Michael addition reactions and its iron(iii) complex as promoter for alkyl oxidation reactions. Catal. Sci. Technol. 2016, 6, 1410-1416. [CrossRef]

2. Khalil, K.; Al-Matar, H.; Elnagdi, M. Chitosan as an eco-friendly heterogeneous catalyst for Michael type addition reactions. A simple and efficient route to pyridones and phthalazines. Eur. J. Chem. 2010, 1, 252-258. [CrossRef]

3. Khalil, K.D.; Al-Matar, H.M. Chitosan Based Heterogeneous Catalyses: Chitosan-Grafted-Poly(4-Vinylpyridne) as an Efficient Catalyst for Michael Additions and Alkylpyridazinyl Carbonitrile Oxidation. Molecules 2013, 18, 5288-5305. [CrossRef]

4. Mallesham, B.; Raikwar, D.; Shee, D. Chapter 1-The Role of Catalysis in Green Synthesis of Chemicals for Sustainable Future; Advanced Functional Solid Catalysts for Biomass Valorization; Hussain, C.M., Sudarsanam, P., Eds.; Elsevier: Amsterdam, The Netherlands, 2020; pp. 1-37.

5. Kim, Y.; Li, C.-J. Perspectives on green synthesis and catalysis. Green Synth. Catal. 2020, 1, 1-11. [CrossRef]

6. Jiang, S.; Cao, W.-B.; Li, H.-Y.; Xu, X.-P.; Ji, S.-J. Convenient synthesis of spiroindolenines from tryptamine-derived isocyanides and organic azides by cobalt catalysis in pure water. Green Chem. 2021, 23, 2619-2623. [CrossRef]

7. Dekamin, M.G.; Eslami, M. Highly efficient organocatalytic synthesis of diverse and densely functionalized 2-amino-3-cyano-4Hpyrans under mechanochemical ball milling. Green Chem. 2014, 16, 4914-4921. [CrossRef]

8. Valizadeh, H.; Fakhari, A. Facile, efficient, and eco-friendly synthesis of benzo[b]pyran-2-imines over MgO and transformation to the coumarin derivatives. J. Heterocycl. Chem. 2009, 46, 1392-1395. [CrossRef]

9. Mirzaei, H.; Davoodnia, A. Microwave Assisted Sol-Gel Synthesis of MgO Nanoparticles and Their Catalytic Activity in the Synthesis of Hantzsch 1,4-Dihydropyridines. Chin. J. Catal. 2012, 33, 1502-1507. [CrossRef]

10. Kumar, D.; Reddy, V.B.; Mishra, B.G.; Rana, R.; Nadagouda, M.N.; Varma, R.S. Nanosized magnesium oxide as catalyst for the rapid and green synthesis of substituted 2-amino-2-chromenes. Tetrahedron 2007, 63, 3093-3097. [CrossRef]

11. Bartley, J.K.; Xu, C.; Lloyd, R.; Enache, D.; Knight, D.W.; Hutchings, G.J. Simple method to synthesize high surface area magnesium oxide and its use as a heterogeneous base catalyst. Appl. Catal. B: Environ. 2012, 128, 31-38. [CrossRef]

12. Gower, L.B. Biomimetic Model Systems for Investigating the Amorphous Precursor Pathway and Its Role in Biomineralization. Chem. Rev. 2008, 108, 4551-4627. [CrossRef]

13. Morin-Crini, N.; Lichtfouse, E.; Torri, G.; Crini, G. Applications of chitosan in food, pharmaceuticals, medicine, cosmetics, agriculture, textiles, pulp and paper, biotechnology, and environmental chemistry. Environ. Chem. Lett. 2019, 17, 1667-1692. [CrossRef]

14. Doustkhah, E.; Rostamnia, S.; Gholipour, B.; Zeynizadeh, B.; Baghban, A.; Luque, R. Design of chitosan-dithiocarbamate magnetically separable catalytic nanocomposites for greener aqueous oxidations at room temperature. Mol. Catal. 2017, 434, 7-15. [CrossRef]

15. Di Carlo, G.; Curulli, A.; Toro, R.G.; Bianchini, C.; De Caro, T.; Padeletti, G.; Zane, D.; Ingo, G.M. Green Synthesis of Gold-Chitosan Nanocomposites for Caffeic Acid Sensing. Langmuir 2012, 28, 5471-5479. [CrossRef]

16. Hardy, J.J.E.; Hubert, S.; Macquarrie, D.J.; Wilson, A.J. Chitosan-based heterogeneous catalysts for Suzuki and Heck reactions. Green Chem. 2003, 6, 53-56. [CrossRef]

17. Singidi, R.R.; RajanBabu, T.V. Borostannylation of Alkynes and Enynes. Scope and Limitations of the Reaction and Utility of the Adducts. Org. Lett. 2010, 12, 2622-2625. [CrossRef] [PubMed]

18. Makhubela, B.C.E.; Jardine, A.; Smith, G. Rh(i) complexes supported on a biopolymer as recyclable and selective hydroformylation catalysts. Green Chem. 2011, 14, 338-347. [CrossRef]

19. Alirezvani, Z.; Dekamin, M.G.; Valiey, E. Cu(II) and magnetite nanoparticles decorated melamine-functionalized chitosan: A synergistic multifunctional catalyst for sustainable cascade oxidation of benzyl alcohols/Knoevenagel condensation. Sci. Rep. 2019, 9, 1-12. [CrossRef] [PubMed]

20. Six-Membered Heterocycles: Sections 6.1-6.9. In The Chemistry of Heterocycles; Wiley-VCH Verlag GmbH: Washington, DC, USA, 2003; pp. 222-256.

21. Zeydi, M.M.; Kalantarian, S.J.; Kazeminejad, Z. Overview on developed synthesis procedures of coumarin heterocycles. J. Iran. Chem. Soc. 2020, 17, 3031-3094. [CrossRef]

22. Irfan, A.; Rubab, L.; Rehman, M.U.; Anjum, R.; Ullah, S.; Marjana, M.; Qadeer, S.; Sana, S. Coumarin sulfonamide derivatives: An emerging class of therapeutic agents. Heterocycl. Commun. 2020, 26, 46-59. [CrossRef]

23. Valentina, M.; David, A.E. Recent Advances in Microwave-Assisted Synthesis of Heterocyclic Compounds. Curr. Org. Synth. 2005, 2, 333-375.

24. Al-Sagheer, F.; Merchant, S. Visco-elastic properties of chitosan-titania nano-composites. Carbohydr. Polym. 2011, 85, 356-362. [CrossRef]

25. Al-Sagheer, F.; Muslim, S. Thermal and Mechanical Properties of Chitosan/SiO2Hybrid Composites. J. Nanomater. 2010, 2010, 1-7. [CrossRef]

26. Li, P.-C.; Liao, G.; Kumar, S.R.; Shih, C.-M.; Yang, C.-C.; Wang, D.-M.; Lue, S.J. Fabrication and Characterization of Chitosan Nanoparticle-Incorporated Quaternized Poly(Vinyl Alcohol) Composite Membranes as Solid Electrolytes for Direct Methanol Alkaline Fuel Cells. Electrochim. Acta 2016, 187, 616-628. [CrossRef]

27. Al-Fulaij, O.; Elassar, A.-Z.A.; Alsagheer, F. Utility of newly modified chitosan in the removal of heavy metal ions from aqueous medium: Ion selectivity, XPS and TGA. Bull. Mater. Sci. 2019, 42, 1-12. [CrossRef] 
28. Gieroba, B.; Sroka-Bartnicka, A.; Kazimierczak, P.; Kalisz, G.; Lewalska-Graczyk, A.; Vivcharenko, V.; Nowakowski, R.; Pieta, I.S.; Przekora, A. Spectroscopic studies on the temperature-dependent molecular arrangements in hybrid chitosan/1,3- $\beta$-D-glucan polymeric matrices. Int. J. Biol. Macromol. 2020, 159, 911-921. [CrossRef]

29. Desimoni, E.; Brunetti, B. X-Ray Photoelectron Spectroscopic Characterization of Chemically Modified Electrodes Used as Chemical Sensors and Biosensors: A Review. Chemosensors 2015, 3, 70-117. [CrossRef]

30. Vieira, R.S.; Oliveira, M.L.M.; Guibal, E.; Rodríguez-Castellón, E.; Beppu, M.M. Copper, mercury and chromium adsorption on natural and crosslinked chitosan films: An XPS investigation of mechanism. Colloids Surf. A: Physicochem. Eng. Asp. 2011, 374, 108-114. [CrossRef]

31. Singh, V.P.; Rath, C. Passivation of native defects of $\mathrm{ZnO}$ by doping $\mathrm{Mg}$ detected through various spectroscopic techniques. RSC Adv. 2015, 5, 44390-44397. [CrossRef]

32. Raghuvanshi, D.S.; Singh, K.N. Microwave-assisted one-pot synthesis of functionalized pyrimidines using ionic liquid. J. Heterocycl. Chem. 2011, 48, 582-585. [CrossRef]

33. Rong, L.; Han, H.; Gao, L.; Dai, Y.; Cao, M.; Tu, S. Efficient and Facile Synthesis of 2,4-Diamino-6-arylpyrimidine-5-carbonitrile Under Solvent-Free Conditions. Synth. Commun. 2010, 40, 504-509. [CrossRef]

34. Deshmukh, M.; Salunkhe, S.; Patil, D.; Anbhule, P. A novel and efficient one step synthesis of 2-amino-5-cyano-6-hydroxy-4-aryl pyrimidines and their anti-bacterial activity. Eur. J. Med. Chem. 2009, 44, 2651-2654. [CrossRef] [PubMed]

35. Bararjanian, M.; Balalaie, S.; Rominger, F.; Barouti, S. A Novel and Efficient One-Pot Synthesis of 2-Aminopyrimidinones and Their Self-Assembly. Helvetica Chim. Acta 2010, 93, 777-784. [CrossRef]

36. Khurana, J.M.; Nand, B.; Saluja, P. DBU: A highly efficient catalyst for one-pot synthesis of substituted 3,4-dihydropyrano[3,2c]chromenes, dihydropyrano[4,3-b]pyranes, 2-amino-4H-benzo[h]chromenes and 2-amino-4H benzo[g]chromenes in aqueous medium. Tetrahedron 2010, 66, 5637-5641. [CrossRef]

37. Jin, T.-S.; Zhang, J.-S.; Liu, L.-B.; Wang, A.-Q.; Li, T.-S. Clean, One-Pot Synthesis of Naphthopyran Derivatives in Aqueous Media. Synth. Commun. 2006, 36, 2009-2015. [CrossRef]

38. Bobal, P.; Bobálová, J. An Efficient Chemoselective Reduction of Furan Series Unsaturated Dinitriles. Molecules 2013, 18, $2212-2221$. [CrossRef] 